Vozes femininas da

liberação do erotismo

(Momentos selecionados

na poesia brasileira)

Angélica Soares* 
Nas duas últimas décadas multiplicou-se, no Brasil, o número de poetisas que têm o erotismo como tema. Ao mesmo tempo, editaram-se sérias pesquisas sobre a sexualidade da mulher brasileira, como a de B ranca Moreira Alves e equi$\mathrm{pe}^{1}$, cujos primeiros resultados já evidenciavam que, não raro, a repressão sexual da mulher leva-a à solidão, à passividade e ao conformismo e a de Rose Marie Muraro $^{2}$, que mostra como a dominação de classes tem por fundamento a dominação sexual.

A dimensão da sexualidade foi, desde as primeiras organizações feministas brasileiras, em 1975, forte componente das preocupações e da luta pela emancipação feminina.

O grande investimento poético no erotismo pelas mulheres parece-me ter muito a ver com esse momento de intenso trabalho de conscientização da necessidade de ruptura dos paradigmas repressores. Ao radicalizar os modos libertários de vivenciar o desejo, o poema acena com uma via de construção identitária e de redimensionamento das relações entre homem e mulher.

Neste ensaio, abordaremos poemas selecionados entre os mais representativos da temática erótica de autoria feminina, com apoio na teoria crítica feminista, especialmente no que se refere a questões de gênero, tendo em vista que:

Como um campo de possibilidades interpretativas, o corpo é o ensejo do processo dialético de interpretar de novo um conjunto histórico de interpreta-

1 ALVES, Branca M oreira et alii. Sexualidade feminina: algumas considerações sobre identidade sexual e identidade social. Escrita/Ensaio, São Paulo, 5: 104-7, 1979. 
ções, que já deram conteúdo ao estilo corporal. O corpo torna-se um nexo peculiar de cultura e escolha e "existir" o próprio corpo torna-se um modo pessoal de examinar e interpretar normas de gênero recebidas ${ }^{3}$.

Por outro lado, a constância de uma escrita do corpo em interação com a Natureza, pela criação de imagens que decorrem de um processo de transformação, permuta e cumplicidade, leva-nos a uma leitura ecológica do desejo, que será feita com base na proposta de F élix Guattari ${ }^{4}$, segundo a qual o equilíbrio global só será alcançado através do inter-relacionamento das três ecologias (do meio ambiente, do social e da subjetividade). I sto porque as imagens poéticas remetem, simultaneamente, para a interação $\mathrm{H}$ omem/Natureza e para relacionamentos interpessoais mais humanitários. Estes, por sua vez, estão intimamente ligados ao fortalecimento mental e emocional. Ainda com amparo na ecosofia guattariana, propõe-se que, pela ruptura dos limites da ideologia falocêntrica, os textos eróticos, construídos conforme os selecionados, inscrevem a desmarcação de espaços fixados pelo patriarcalismo e pela moral sexual cristã, remetendo o leitor para a possibilidade de constituição de "Territórios Existenciais"5 na relação erótica ressingularizada.

Comecemos por demonstrar essa minha perspectiva crítica, ressaltando o caráter fortemente telúrico da poesia de Myriam Fraga, aqui testemunhado por "Semeadura":

O limite da luz

é o espaço do salto.

É a casa do sonho,

o caminho de volta,

extravio ou derrota.

O pássaro é este silêncio

cortando como faca.

É a bicada no ventre:

semeadura de mel

nos meus campos molhados.

2 MURARO, Rose Marie. Sexualidade da mulher brasileira; corpo e classe social no Brasil. 4. ed. Petrópolis: Vozes, 1983.

3 BUTLER, J udith. Variações sobre sexo e gênero: Beauvoir, Wittig e Foucault. In: BENHABIB, Leyla \& CORNELL, Orucilla; (orgs.) Feminismo como crítica da modernidade. Trad. Nathanael da Costa Caixeiro. Rio de J aneiro: Rosa dos Tempos, 1987. p. 139-54.Ver p. 145. 


\begin{abstract}
Oh ! eterno seja o passo
minha pele no teu aço,

ó pássaro, pássaro.

Senhor do sol me arrebata,

ó pássaro,

tuas garras como arado

revolvendo meus pedaços.

M eu corpo de sementeira

na raiz do teu abraço.

Um arco-íris de espigas

no meu seio, meu regaço

como um odre

na esperança de teu vinho,

meu canto no teu cansaço

ó pássaro, pássaro ${ }^{6}$.
\end{abstract}

Aí, a dicção vocativa indica, na figura do "pássaro", o apelo a um sentimento prestes a eclodir intensa e abertamente. I magem da libido desreprimida, "o espaço do salto" se vislumbra iluminado ("o limite da luz"), mas oscilante no "sonho". No final da caminhada, o prazer atingido traz a alegria ("meu canto") e o esgotamento ("teu cansaço").

A "Semeadura" erótica ressalta, no "corpo de sementeira" da mulher, o "ventre" e o "seio". E, para que os "campos molhados" (o feminino) se fertilizem, é necessário o "arado" (o masculino) a revolver-lhe os "pedaços".

Como vemos, a poetisa baiana recria a relação amorosa, investindo na figurização do prazer de um "eu" feminino, que tem a Natureza como fonte e motivo. São imagens ao mesmo tempo corpóreas e espirituais, porquanto o vôo do pássaro tem chegado até nós, pelos mitos ou pela literatura, como símbolo das relações entre o celeste e o terreno e sua leveza aparece-nos, constantemente, como libertação do peso terrestre, como o levantar vôo da alma7 .

Natureza do corpo e corpo da Natureza convergem no poema, muito sugestivamente ainda, em "raiz do teu abraço" e "arco-íris de espigas do meu seio", a comporem o quadro do amor bem realizado; no pensamento guattariano: territorializado existencialmente.

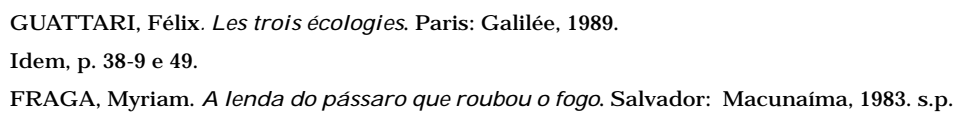


E m Magma, de O Iga Savary, se concentra, de forma intensiva, a mímesis literária da linguagem dos corpos, naquele modo de ser em que na $\mathrm{N}$ atureza se reconhece a natureza humana. Constantemente, produzem-se imagens ecológicas do que Marcuse conceituou como "realidade erótica em que os instintos vitais acabassem descansando na gratificação sem repressão"8:

\footnotetext{
Quando abro o corpo à loucura, à correnteza,

reconheço o mar em teu alto búzio

vindo a galope, enquanto cavalgas lento

meu corredor de águas.
}

A boca perdendo a vida sem tua seiva,

os dedos perdendo tempo enquanto

para o amado a amada se abre em flor e fruto

(não vês que esta mulher te faz mais belo?).

\begin{abstract}
A vida no corpo alegre de existir,
fiquei à espreita dos grandes cataclismos:

daí beber na festa do teu corpo

que me galga esse castelo de águas ${ }^{9}$.
\end{abstract}

Perfeitamente inseridos na dinâmica natural, os corpos dos amantes se conectam e se complementam, na entrega plena e recíproca. P ela integração entre o ser humano e a Natureza, a linguagem dos corpos não é apenas deles, mas do mar, do animal, da flor, do fruto... em expressão desreprimida e desrepressora.

Estruturando-se explicitamente como ultrapassagem do ser pessoal e do limite ("loucura”, “correnteza”, “galope”, “perdendo a vida”, “cataclismos") , a vida atinge a exuberância, no dinamismo próprio de E ros, que leva à volúpia. Assim, o erotismo configura-se como a vivência fugaz da substituição, em vida, do “isolamento do ser, da sua descontinuidade por um sentimento de continuidade profunda"10, vivência fortemente enriquecedora, porque promotora do questionar e do conhecer.

Mudando a perspectiva vigente ditada pelo modelo masculino dominante, a fala feminina marca uma de suas diferenças na apresentação do homem como objeto de desejo, ressaltando-Ihe a beleza, que é intensificada pela participação

\footnotetext{
CHEVALIER, J ean \& GHEERBRANT, Alain. Dicionário de símbolos; mitos, sonhos, costumes, gestos, formas, figuras, cores, números. Trad. Vera da Costa e Silva et alii. 3. ed. Rio de J aneiro: J osé Olympio, 1990.p. 687-8.

8 MARCUSE, Herbert. Eros e civilização; uma crítica filosófica ao pensamento de Freud. Trad. Álvaro Cabral. Rio de J aneiro: Zahar, 1968. p. 136.
} 
ativa da mulher no ato amoroso. A atuação transformadora da mulher é indício, no poema, de outro modo de rompimento da tradição opressiva.

A indicação da "festa", integrante das últimas imagens, encaminha-nos para o sentido da transgressão erótica, sem a qual não se experimenta o "sentimento de liberdade, necessária à plenitude do ato sexual"11. A ssim se completa o quadro da liberação, a apontar para a ressingularização de maneiras íntimas de ser e de relacionar-se psico-corporalmente; o que na ótica guattariana, seria imprescindível para a constituição de um "Território Existencial". E nele se deve mais investir na promoção de relacionamentos que marquem a diferença feminina, sem as hierarquias opressoras.

Como no poema anteriormente abordado, é comum, na poesia brasileira de autoria feminina, na qual se recria a liberação do desejo, a figurização da mulher como sujeito da cena erótica. E isso nos interessa, sobremaneira, por indicar o caráter desconstrutor da representação estereotipada de feminino e masculino, sustentada pelas tecnologias de gênero patriarcais, que reduplicam a percepção essencialista de uma feminilidade e uma masculinidade "naturais". Essa percepção, calcada em fatores biológicos, encobre, ideologicamente, a sua verdadeira existência, como uma construção cultural ${ }^{12}$.

Em “Canícula”, de Adélia Prado, essa postura assim se textualiza:

Ao meio dia, deságua o amor

Os sonhos mais frescos e instigantes;

estou onde estão as torrentes.

Ao redor da casa grande espaça um quintal sem cercas

tomado de bananeiras, só bananeiras,

altas como coqueiros.

Chego e é na beira do mar encrespado de correntezas,

sorvedouros azuis.

Há um perigo sobre faixa exígua

que é de areia e é branca

Quero braceletes

e a companhia do macho que escolhi ${ }^{13}$.

O sentido de correspondência entre a realização amorosa e a da Natureza leva a que se identifique, inicialmente, no poema, a primeira por uma ação pró-

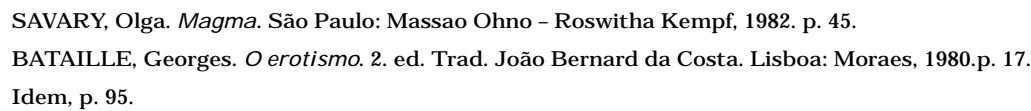


pria da segunda: o desaguar, que situa o "eu" em perfeita consonância com a dinâmica natural, quer em sua organização tranqüila ("bananeiras" no "quintal”), quer em seu manifestar-se violento ( “...o mar, encrespado de correntezas / sorvedouros azuis").

Se, numa possível leitura, associarmos a idéia do "perigo" (versos 9 e 10) às declarações abruptas dos dois versos finais, onde o 'eu' tem a palavra decisiva, surpreenderemos, nas entrelinhas, o fato de que o "perigo" poetizado não é apenas físico (da violência das "correntezas" e "sorvedouros"), mas também social (da subversão da imagem masculina como agente da escolha). E note-se que, respondendo ao estilo impactante do discurso adeliano, a opção pelo signo "macho" reforça a intenção transgressora da voz feminina.

De E unice Arruda, "Tema II" intensifica, pelo recurso da anáfora, o caráter consciente e con-si derado do exercício erótico, aí textualizado como um "ritual" solidário, na marcação do nós:

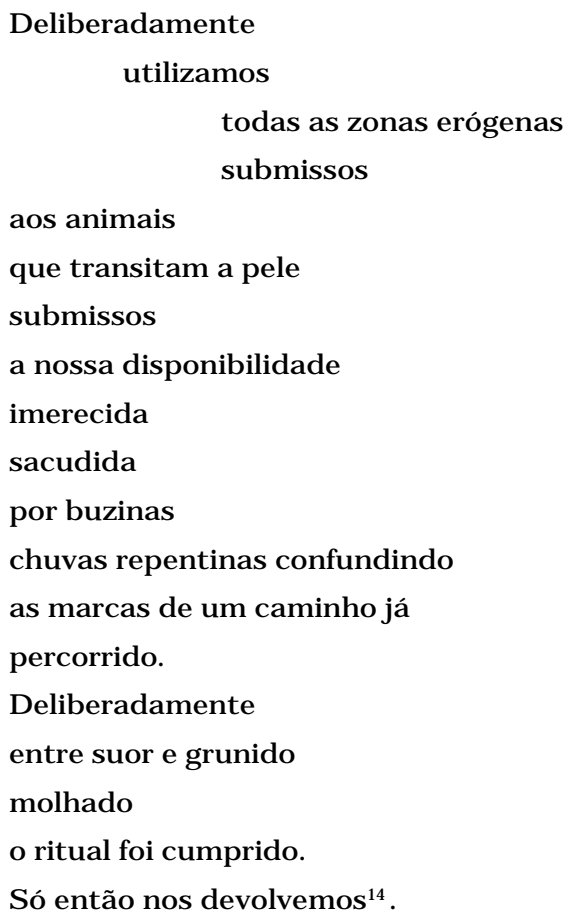

O sexo, não mais dividido e discriminador, é agora transcrito como uma ação realizada a dois, em que o predomínio da genitalização da sexualidade masculina é substituído pela fruição livre de "todas as zonas erógenas", a nos permitir pen- 
sar o erotismo para além da função procriadora - a única facultada à mulher pela moral sexual cristã.

É a poematização do que Rose Marie Muraro denominou de "solidariedade radical"15, que caracterizaria o desejo libertário (erótico) em oposição ao desejo de dominação ( vindo da pulsão de morte, conforme concebida por F reud) .

Simultaneamente, o prazer, também pelos caminhos da "pele", se sobrepõe ao significado reprodutivo - sustentado ainda por estratégias de dominação falocêntricas, embora estas já não sejam tão eficientes neste momento histórico de ruptura dos paradigmas ideológicos.

A reciprocidade do gozo promove a rememoração do fazer agregador de E ros e, nos inserindo nas ocorrências ambientais, conduz-nos simbolicamente na direção do inter-relacionamento ecológico.

Ao recorrer às manifestações animais para textualizar as sensações e reações eróticas, E unice Arruda nos remete para B ataille, quando nos alerta para o fato de que, embora comece o erotismo “onde o animal acaba, a animalidade é sempre o seu fundamento. Desse fundamento a humanidade desvia-se com horror, embora, ao mesmo tempo, o mantenha"16.

A poesia de Suzana Vargas, em diversas passagens, parece-nos também remeter, sutilmente, para as três ecologias, permitindo-nos aprofundar a apreensão de seu complexo imagístico. Vejamos um exemplo:

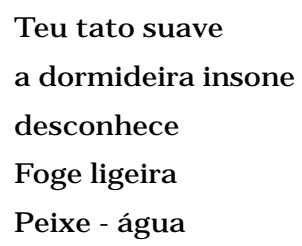

$$
\begin{aligned}
& \text { Águia - ar } \\
& \text { São meus espaços } \\
& \text { que procuro em teu corpo } \\
& \text { Acordo em }
\end{aligned}
$$

Clara luz aquática

que se despe e

te sucede. ${ }^{17}$

Nessas positivas "Vibrações" varguianas, os "espaços" da interioridade se transmitem por elementos ambientais e se delineiam claros, transparentes, aber-

\footnotetext{
org. Tendências e impasses; o feminismo como crítica da cultura. Rio de J aneiro: R occo, 1994. p. $206-42$.

PRADO, Adélia. O coração disparado. 4. ed. Rio de J aneiro: 1987. p. 55.

SAVARY, Olga (org.) Carne viva; primeira antologia brasileira de poemas eróticos. Rio de J aneiro: Anima, 1984. p. 117.
} 
tos para o que "sucede" o encontro no corpo do outro. Dessa forma, projeta-se o sentido esclarecedor da relação erótica prazerosa ( veja a leveza e a suavidade das imagens) para além de um e de outro amante, processando-se um prolongamento de sua atuação, no socius. E isto se explica porque a identificação do espaço de cada ser humano é uma prática relacional (veja a terceira estrofe).

Pelo recurso da ambigüidade lingüística, na primeira estrofe, sujeito e objeto se confundem, assim como se sentem desfeitos os seus limites, no erotismo. A fugacidade desse sentimento de dissolução, promovido pela fusão dos corpos, se metaforiza nas noções de fluidez e agilidade que estruturam a segunda estrofe.

Na última estância, atinge-se o ápice da indicação clarificadora do erotismo, associando-se o sentido de acordar (que é também o de descobrir, posto em posição antitética com o desconhecer da primeira estrofe) à redundância poética de "Clara luz aquática /que se despe...".

Maramar, de Helena Parente Cunha, detém-nos em um poema onde, ao se verbalizar a correspondência cósmica no erotismo (como já sugere o neologismo que compõe o título do livro) se desfaz a territorialização repressiva dos papéis sexuais.

\section{ai frui}

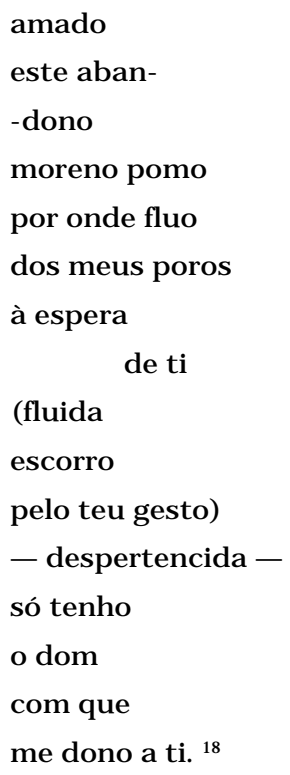

No fazer-se "fluida" para escorrer pelo gesto do amante, a mulher sente-se "despertencida" e só então pode dar-se espontaneamente. 
A terminação "-dono", ressaltada na marcação gráfica de "aban-/-dono", por um “dom", à fruição do outro, afasta da relação o sentido de domínio, redimensionando-a como uma entrega voluntária. Esse redimensionamento literário é reforçado pelo emprego, no último verso, de "me dono", remetendo para o dar-se, muito diferentemente do sujeitar-se a uma dominação.

É interessante observar que o ludismo da construção, unindo o pronome da primeira pessoa "me" à forma "dono", insere a mulher (que é, na ótica androcêntrica, vista como objeto a ser possuído sexualmente ) num modo poético de possuir, sem a conotação machista, porque, simultaneamente, ela se dá ("me dono a ti"). Ser "dono", doando-se, indica, no discurso experimental de Helena Parente Cunha, a tática ideal do jogo erótico. Nessa tática, não se trata de inverter o sistema, passando a mulher de dominada à dominadora, mas de desaguar em uma nova forma, compartida, de relacionamento erótico.

Em "Fontes", de Lya Luft, a insistência na sugestividade da figurização do brotar das águas se faz o veículo de revivência da verdade mítica, erótica /ecológica (veja a versão erótica do mito cosmogânico) que participa, desde sempre, da dinâmica do nosso imaginário:

\footnotetext{
Como fontes que de noite mansamente boca a boca trocam seus segredos d' água, o amor que fosse o transparente afago da mútua solidão, teria ainda a lúcida paixão oculta dessas águas. E nós, trêmulas bocas de fontes sequiosas deixamos que brotem, fundam-se, retornem, os silêncios do amor como num lago. ${ }^{19}$
}

A partir do símile inicial, que remete para as origens do amor, desaparecem os limites de "fontes" e "bocas"; o que irá explicitar-se no sexto verso, na poetização da saciedade da sede de paixão.

Poderíamos afirmar, com Angelo R icci que, pela consciência da N atureza em nós, a carga imaginal do erotismo leva a poetisa a fecundar as imagens externas,

... vivificando-as, porém, humanamente, com o fundo do seu ser participando da Natureza: o apelo, a solicitação, o chamamento que vêm de fora, ativamente da Natureza, hão de produzir uma conciliação entre o verdadeiro e o real: o verdadeiro humano e o real da Natureza ${ }^{20}$.

6 BATAILLE, Georges, cit. p. 84.

17 VARGAS, Suzana. Sempre noiva. Rio de J aneiro: Achiamé, 1984.p. 33. 
Essa conciliação permite que se recrie, no texto, através da plasticidade das figuras aquáticas, do paralelismo musical dos versos e do jogo antitético entre ocultação e transparência, a mansidão de um amor que se configura como "lúcida paixão".

Pela livre participação da subjetividade, parece-nos indicar o poema, que os amantes se tornam disponíveis ao brotar, ao fundir e ao retornar eróticos. Sob o signo de Eros, até a solidão se faz mútua, a resgatar a essência relacional do ser humano.

De Hilda Hilst, chama-nos a atenção a auto-reflexão, no feminino, da renovação colorida da vida através do ressurgimento do amor, cuja fonte da simbologia é a N atureza:

Amor chagado, de púrpura, de desejo

Pontilhado. Volto à seiva de cordas.

Da guitarra, e recheio de sons o teu jazigo.

Volto empoeirada de vestígios, arvoredo de ouro

Do que fomos, gotas de sal na planície do olvido

Para reacender a tua fome.

A mor de sombras de ocasos e de ovelhas.

Volto como quem soma a vida inteira

A todos os outonos. Volto novíssima incoerente

Cógnita

Como quem vê e escuta o cerne da semente

E da altura de dentro já lhe sabe o nome

E reverdeço

No rosa de umas tangerinas

E nos azuis de todos os começos ${ }^{21}$.

Convém ressaltar, na leitura do poema, a familiaridade com que o 'eu' se sente Natureza, quando se deixa encaminhar por Eros. Desse modo, o recomeçar amoroso é sempre um reverdecer. E o que nos parece, às vezes, tão distante, revela-se poeticamente dentro de nós, indiciando uma consciência ecológica radical, livre das setorizações e dos confrontos, que bloqueiam o equilíbrio global.

Ao nos reconhecer na N atureza, a desvelamos reconhecidamente humana. E tornamos possível viver "os azuis de todos os começos"; assim, então, guattarianamente despoluídos. 
No exercício erótico, que é sempre o de uma busca psicológica de auto-conhecimento, $\mathrm{Hilda} \mathrm{H}$ islt enfatiza a prática do retorno (veja a insistência na forma verbal "volto"), assumida pela amante. Com isso, desvela, também, na poematização do erotismo, a participação ativa da mulher, rompendo-se o sentido da passividade "natural" a ela atribuída pelo sistema essencialista e universalizante de sexo-gênero, que impõe, ainda hoje, um posicionamento do homem como sujeito e da mulher como sujeitada ${ }^{22}$.

Ao estilo hilstiano, essa é, portanto, uma mensagem ética e estética motivada pela liberação do desejo e dela, simultaneamente, motivadora.

Como vemos, por esta pequena amostragem, a criação e a divulgação pela mulher de uma poesia radicalizadora de modos libertários de vivência conjunta do prazer integram a consciência ecológica, no seu sentido mais globalizante, visto que as imagens do corpo livre para o gozo e em harmonia com a Natureza contrapõem-se aos mecanismos repressores da subjetividade e, conseqüentemente, aos da socialidade.

Os poemas nos sugerem, de algum modo, que o sentimento compartilhado de satisfação do desejo não é apenas ponto de chegada da experiência erótica, mas também marco de partida para o equilíbrio global.

\section{R eferência Bibliográfica}

HESíODO. Teogonia. 2. ed. Trad. do original grego e coment. Ana Lucia Cerqueira e Maria Therezinha A rêas Lyra. Niterói:E duff, 1986.

RICCI, Angelo. Apresentação. In: DUFRENNE, Mikel. O poético. Porto Alegre: Globo, 1969. p. IX-XVII.p. XIII. HILST, Hilda. Do desejo. Campinas: Pontes, 1992. p. 43.

MOI, Toril. Feminist, Female, feminine. In: . et alii. The feminist reader. London: Macmillan Press Ltd, 1989. p. $117-32$ 